\title{
Intermittent High Glucose Enhances the Proliferation of Rat Aortic Vascular Smooth Muscle Cells More Than Constant High Glucose via the Mitogen-Activated Protein Kinase Pathway
}

\author{
Sung Hoon $\mathrm{Yu}^{1, *}$, Hyung Joon $\mathrm{Yoo}^{2, *}$, Dong Hyun Kang ${ }^{2}$, Shin Je Moon ${ }^{2}$ Jae Myung $\mathrm{Yu}^{2}$ \\ ${ }^{1}$ Division of Endocrinology and Metabolism, Hanyang University College of Medicine, Seoul, ${ }^{2}$ Division of Endocrinology and Metabolism, \\ Hallym University College of Medicine, Seoul, Korea
}

Corresponding Author: Sung Hoon $\mathrm{Yu}, \mathrm{MD}, \mathrm{PhD}$ Division of Endocrinology and Metabolism, Hanyang University Guri Hospital, Hanyang University Colleg of Medicine, 153 Gyeongchun-ro, Guri 11923, Korea

Tel: $+82-31-560-2154$ Fax: +82-31-560-2189

E-mail:

physicianyu@daum.net

*These authors contributed equally to this study and should be considered co-first authors.

Received: July 1, 2017 Revised: August 3, 2017 Accepted: August 23, 2017
Background: The acute glucose fluctuations in diabetes can be a risk factor of cardiovascular events. Nonetheless, the mechanism of action of intermittent hyperglycemia on the proliferation of vascular smooth muscle cells (VSMCs) is poorly understood. We compared the effects of exposure to constant and intermittent hyperglycemia on in vitro proliferation of aortic VSMCs from obese diabetic rats. Methods: VSMCs from Otsuka Long-Evans Tokushima Fatty (OLETF) rats were incubated for 72 hours with different glucose concentrations: a constant normal-glucose medium (4.8 $\mathrm{mM})$, constant highglucose medium (24.5 mM), normal- and high-glucose media alternating every 12 hours, and mannose (12.0 $\mathrm{mM}$; an osmotic control for high glucose levels). The proliferation of VSMCs was analyzed by a 3-[4,5-dimethylthiazol-2-yl]-diphenyltetrazolium bromide (MTT) assay. The molecular mechanism (including phospho-p44/42 mitogen-activated protein kinase [MAPK], mitogen-activated protein kinase kinase-1/2 (MEK1/2), Protein kinase B (Akt), and the apoptosis pathway) was then studied. Results: We detected enhanced proliferation of VSMCs incubated with the constant or intermittent high-glucose medium using the MTT assay $(p<0.05)$. The proliferation of VSMCs was more pronounced in the intermittent high-glucose environment than at a constant high glucose concentration. In western blot analysis, treatment with the constant high-glucose medium for 72 hours increased phospho-p44/42 MAPK and phospho-MEK1/2 expression as compared to treatment with the normal-glucose medium. These effects were further enhanced by the intermittent high glucose concentration. Akt and phospho-Akt were not affected by hypergly cemia. In the apoptotic pathway, Bcl- $\mathrm{x}_{\mathrm{L}}$, phospho-Bad, and caspase- 3 were not affected by hyperglycemia for 72 hours. Conclusion: Hyperglycemia increased the proliferation of VSMCs from OLETF rats via the MAPK pathway. These effects were further enhanced by intermittent exposure to the high glucose concentration.

Key Words: Intermittent high glucose, Vascular smooth muscle cell, Mitogen-activated protein kinase, Apoptosis

\section{INTRODUCTION}

Diabetes mellitus is an important risk factor of cardiovascular disease ${ }^{1,2)}$. The progression of atherosclerosis of blood vessels is a characteristic complication in diabetic patients ${ }^{3)}$. Many studies have compared the roles of different factors in diabetic vascular complications; however, their precise mechanisms are still unclear ${ }^{4)}$. As demonstrated by many studies, macrovascular and microvascular complications depend on hyperglycemia ${ }^{5)}$.

Hyperglycemia can increase inflammation and proliferation of atherosclerotic lesions in coronary arteries ${ }^{1,6,7)}$. Diabetes mellitus aggravates these processes by upregulating atherogenicity and oxidative stress of vascular smooth muscle cells (VSMCs) ${ }^{1,8)}$. VSMC proliferation is an important step in the development of atherosclerotic lesions, which induces remodeling of the vascular basement membrane ${ }^{2,9)}$. Chronic hyperglycemia in diabetes has been identified as a risk factor of complications accelerating atherosclerosis. Both fasting and postprandial hyperglycemia contribute to this process.

The fluctuating glucose levels that occur in diabetes can be a risk factor of cardiovascular events. Alternating rather than consistent hyperglycemia provokes an increase in colla- 
gen production by cultured mesangial cells ${ }^{10)}$. There is increasing evidence that glycemic disorders, such as intermittent glucose fluctuations over a short period, may play a significant role in diabetic complications ${ }^{11-13)}$. Nevertheless, the mechanism of action of intermittent hyperglycemia on VSMC proliferation is poorly understood.

The goal of this study was to compare the effects of constant and intermittent high glucose concentrations on the proliferation of rat aortic VSMCs in culture and to identify the signaling pathway associated with the possible change in proliferation and apoptosis.

\section{MATERIALS AND METHODS}

\section{Cell Culture}

VSMCs were harvested from the thoracic aorta of 12week-old male Otsuka Long-Evans Tokushima Fatty (OLETF) rats by elastase and collagenase digestion, as previously described $^{14)}$. The cells were grown in Dulbecco's Modified Eagle's Medium (DMEM, Gibco-BRL, Life Technologies, New York, NY, USA) with $10 \%$ of fetal bovine serum at $37^{\circ} \mathrm{C}$ and $5 \%$ $\mathrm{CO}_{2}$ in a humidified incubator. At confluence, the cells were trypsinized with $0.125 \%$ trypsin in $0.005 \%$ ethylenediaminetetraacetic acid (EDTA). The cells from passages 7-10 were used for the experiments. The cells grew in the "hill and valley" pattern that is characteristic of VSMCs in culture and showed positive immunostaining for smooth muscle $\alpha$ actin (antibody was from Cell Signaling Technology, Beverly, MA, USA) ${ }^{15)}$.

\section{Experimental Protocol}

VSMCs in the logarithmic growth phase were trypsinized to obtain a single-cell suspension, adjusted to a cell concentration of $105 / \mathrm{mL}$, and transferred into a six-well plate. After the cells reached confluence, the medium was replaced with serum-free DMEM, which was incubated with the cells for 24 hours for synchronization. The cells were then incubated for additional 48 hours in a glucose-specific basic medium. The cells were randomly divided into four groups: (1) constant normal-glucose medium (4.8 mM); (2) constant high-glucose medium (24.5 mM); (3) normal- and high-glucose media alternating every 12 hours; (4) mannose $(11.5 \mathrm{mM}$; an osmotic control for high glucose). All the groups were otherwise subjected to identical conditions, and the experiment was repeated at least 5 times.

\section{Assessment of Cell Proliferation}

Cell proliferation was evaluated by a methylthiazoletetrazolium (MTT, Sigma, St. Louis, MO, USA) assay, and we calculated the cell viability percentage. VSMCs were incubated with various concentrations of glucose $(4.8,25$, or 4.8 and $25 \mathrm{mM}$ alternating every 12 hours). Next, the MTT solution ( $5 \mathrm{mg} / \mathrm{mL}$ in phosphate-buffered saline [PBS]) was added into each plate and incubated for 4 hours. The cells were solubilized by the addition of dimethyl sulfoxide (Sigma), and the absorbance was measured at $570 \mathrm{~nm}$ on an Enzyme-Linked Immunosorbent Assay ELx800 Universal Microplate Reader (Bioteck Instruments Inc., Winooski, VT, USA). A BD FACS Calibur flow cytometer (BD Biosciences, San Jose, CA, USA) was used for flow cytometric analysis of the effects of intermittent or constant hyperglycemia on the proliferation of VSMCs.

\section{Western Blot Analysis}

The cells cultured with normal-glucose $(4.8 \mathrm{mM})$, high-glucose $(25 \mathrm{mM})$, or alternating normal- and high-glucose media for 72 hours were washed and disrupted with lysis buffer (10 mM Tris [pH, 7.4], 1 mM EDTA, 1\% sodium pyrophosphate [NP]-40, $0.1 \mathrm{mM}$ phenylmethylsulfonyl fluoride, $20 \mathrm{nM}$ sodium vanadate, and $1 \times$ cocktail solution). The supernatants were analyzed by the Bradford assay (Bio-Rad, Hercules, CA, USA). Sodium dodecyl sulfate polyacrylamide gel electrophoresis was run in a 10\% resolving gel, followed by transfer to a nitrocellulose membrane (Bio-Rad). The membranes were blocked for 1 hour at room temperature in a blocking solution (5\% skim milk in Tris- $\mathrm{HCl}$ buffer with Tween 20 [TBST, 200 $\mathrm{nM}$ Tris- $\mathrm{HCl}, 500 \mathrm{mM} \mathrm{NaCl}, \mathrm{pH} 7.5,0.05 \%$ Tween 20]), and then incubated overnight at $4^{\circ} \mathrm{C}$ with an anti-phospho-p44/42 MAP kinase (ERK1/2) and anti-phospho-MEK1/2 antibodies (Cell Signaling Technology). The membranes were washed with TBST (5 minutes with 3 changes) and incubated with a peroxidase-conjugated anti-mouse IgG antibody (Amersham Life Science, Buckinghamshire, UK). The membrane was washed and processed using the Visualizer Western Blot Detection Kit (Upstate Cell Signaling Solutions, Lake Placid, NY, USA), and autoradiography was then performed. The band intensity was analyzed by densitometry in the ImageJ software.

Experiments were conducted with western blot analysis. Antibodies were specific to either the antiapoptotic proteins $\mathrm{BCl}-2$ and $\mathrm{BCl}-\mathrm{x}_{\mathrm{L}}$ or the proapoptotic proteins Bad, Bax, and caspase 3 (all supplied by Cell Signaling Technology) ${ }^{16)}$. Cells were washed three times with cold PBS and then lysed for 30 minutes at $4^{\circ} \mathrm{C}$ in a buffer consisting of $1 \%$ Nonidet P-40 and $50 \mathrm{mM}$ Tris- $\mathrm{HCl}(\mathrm{pH}, 7.5), 100 \mathrm{mM} \mathrm{NaCl}, 5 \mathrm{mM}$ EDTA, and $1 \mathrm{mM}$ phenylmethylsulfonyl fluoride. After centrifugation at $13,000 \mathrm{~g}$ for 10 minutes at $4^{\circ} \mathrm{C}$, the supernatant was collected, and the protein content of all the samples was determined by the Bradford assay ${ }^{17)}$ with bovine serum albumin as a standard. Proteins were transferred to a nitrocellulose membrane (Amersham Pharmacia Biotech, Buckinghamshire, UK), blocked for 2 hours in 5\% nonfat dry milk in TBS (50 
$\mathrm{mM}$ Tris- $\mathrm{HCl}, \mathrm{pH} 7.5$, and $150 \mathrm{mM} \mathrm{NaCl}$ ), and washed with TBST, and then incubated at room temperature for 2.5 hours with mouse anti-human $\mathrm{Bcl}-2$ or anti-human Bad antibodies ( $5 \mathrm{mg} / \mathrm{mL}$ ). The filter was later washed with TBST, and detection was carried out using a secondary antibody (horseradish peroxidase-linked anti-mouse lgG antibody; 1:7,000) and the Enhanced Chemiluminescence System (Amersham Pharmacia Biotech), with exposure of Kodak Bio Max Light-1 films. The intensity of the Western blot signals was quantified by densitometry.

\section{Statistical Analysis}

All the experiments were repeated 5 times. Data are expressed as mean \pm standard deviation. Statistical analysis was performed by Student t-test or one-way analysis of variance. The analyses were performed in the SPSS ver. 16.0 (SPSS Inc., Chicago, IL, USA). Differences with a $p$-value of $<0.05$ were considered significant.

\section{Ethics Statement}

The procedures involving animals and their care were conducted in conformity with the institutional guidelines that are in compliance with international laws and policies $(\mathrm{NIH}$ Guide for the Care and Use of Laboratory Animals 8th edi. 2011). The Institutional Review Board of Hallym Medical Center approved this study (HMC2017-1-0404-13).

\section{RESULTS}

\section{The Effect of Intermittent High Glucose Concentration on the Proliferation of VSMCs}

To examine the effect of high glucose concentration on the proliferation of cultured VSMCs, quiescent cultures were exposed to constant or intermittent high glucose concentration. As shown in Fig. 1, high glucose levels stimulated VSMC proliferation in a time-dependent manner. When exposed to constant high glucose concentration, in the MTT assay, VSMC numbers increased compared with cells exposed to the normal glucose concentration (as a control). This effect increased when the cells were exposed to intermittent high glucose concentrations (Figs. 1, 2).

As shown in Fig. 1, exposure to the constant high glucose concentration for 72 hours induced a $51.6 \%$ increase in cell numbers when compared with normal glucose $\left(2.9 \pm 0.1 \times 10^{6}\right.$ cells versus $4.4 \pm 0.1 \times 10^{6}$ cells per well, $p<0.05$ ). When the VSMCs were exposed to intermittent high glucose concentrations compared with the results obtained at the normal glucose concentration, this effect reached a $120 \%$ increase in cell numbers $\left(2.9 \pm 0.1 \times 10^{6}\right.$ cells vs. $6.4 \pm 0.2 \times 10^{6}$ cells per well, $p<0.05$ ).

In fluorescence-activated cell sorter analysis, exposure to intermittent high glucose concentrations induced a $14.5 \%$ increase in the M2 phase when compared with the normal glucose concentration (Fig. 2).

The proliferation of VSMCs did not change significantly during the incubation with mannitol compared to the use of the normal glucose concentration in the MTT assay.

\section{Effects of the Intermittent High Glucose Concentration on the MAPK Pathway}

We tested whether constant or intermittent high glucose concentration alters the mitogen-activated protein kinase (MAPK) pathway in VSMCs. As shown in Fig. 3, after exposure to constant high glucose concentration $(25 \mathrm{mM})$ for 72 hours, phospho-MAP-kinase signals increased as compared to the cells exposed to the normal glucose concentration. Nevertheless, after VSMCs were exposed to the intermittent high concentrations of glucose, phospho-MAP-kinase increased by $61 \% \pm 0.5 \%$ compared to cells exposed to the constant normal glucose level $(p<0.01)$.

Both constant and intermittent high glucose concentrations significantly increased phospho-MAP-kinase and phospho-MEK $1 / 2$ amounts in VSMCs compared to the cells exposed to the normal glucose concentration (relative expression: $1.00 \pm 0.00$ vs. $1.61 \pm 0.05, p<0.01 ; 1.00 \pm 0.00$ vs. $1.26 \pm$ $0.03, p<0.05$, respectively; Fig. 3). Moreover, this effect increased in VSMCs exposed to the intermittent high concentrations of glucose compared to the cells exposed to the constant high glucose level $(1.61 \pm 0.02$ vs. $1.28 \pm 0.02, p<0.05$; Fig. 3).

\section{Effects of Hyperglycemia on the Akt and the NF-kB Pathways}

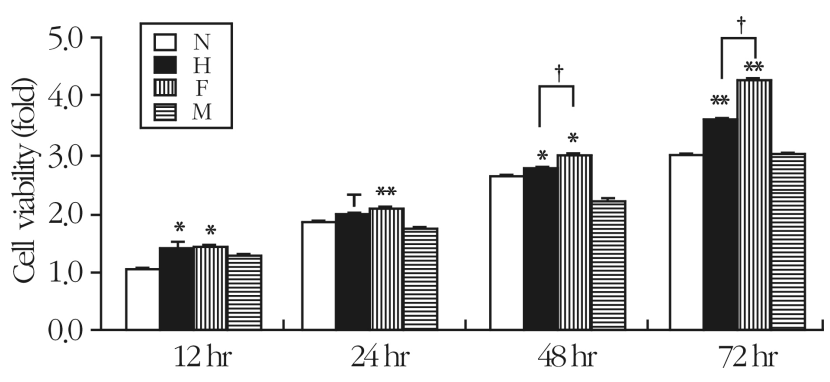

Fig. 1. The effect of glucose fluctuations on the proliferation of vascular smooth muscle cells (VSMCs). Data are expressed as mean \pm standard deviation. $\mathrm{N}$, normal glucose concentration $(4.8 \mathrm{mM})$; H, high glucose concentration $(24.5 \mathrm{mM})$; F, fluctuation of glucose between normal $(4.8 \mathrm{mM})$ and high concentrations $(24.5 \mathrm{mM}) ; \mathrm{M}$, mannitol control $(11.5 \mathrm{mM})$. " $\mathrm{p}<0.05$ vs. $\mathrm{N},{ }^{* *} \mathrm{p}<0.01$ vs. $\mathrm{N} .{ }^{\dagger} \mathrm{p}<0.05$, compare $\mathrm{F}$ with $\mathrm{H}$. 

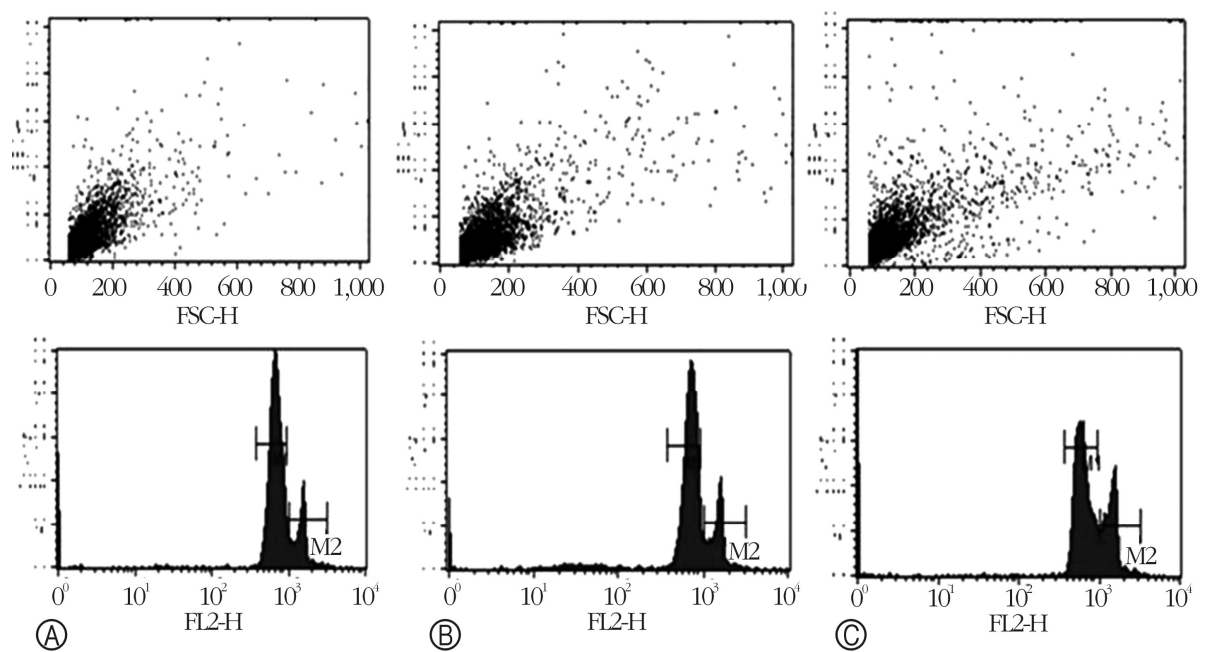

Fig. 2. Fluorescence-activated cell sorting analysis of glucose-treated vascular smooth muscle cells. (A) Normal glucose level $(4.8 \mathrm{mM})$. (B) High glucose concentration $(24.5 \mathrm{mM})$. (C) Fluctuation of glucose between normal $(4.8 \mathrm{mM})$ and high levels $(24.5 \mathrm{mM})$.

We determined whether constant or intermittent high glucose concentration alters the Akt or nuclear factor-kappa $\mathrm{B}(\mathrm{NF}-\mathrm{kB})$ pathway in VSMCs. The expression of PI-3 kinase, Akt, phospho-Akt, and NF-KB was not changed by constant hyperglycemia or intermittent hyperglycemia in OLETF rats (Fig. 3B).

\section{The Effect of Hyperglycemia on the Apoptosis Pathway}

We tested whether constant or intermittent high glucose concentration alters the apoptosis pathway in VSMCs. As shown in Fig. 4, there were no significant changes in $\mathrm{BCl}-\mathrm{x}_{\mathrm{L}}$, $\mathrm{Bcl}-2$, Bax, or caspase 3 after exposure to the constant high glucose concentration compared to the cells exposed to the normal glucose level. This effect was the same after the exposure of VSMCs to the intermittent high concentrations of glucose compared to the cells exposed to the constant normal glucose level. Nonetheless, the expression of phosphoBad increased slightly during intermittent hyperglycemia.

\section{DISCUSSION}

This work shows that cultured aortic VSMCs of OLETF rats exposed to high glucose concentrations manifest enhanced cell proliferation, MAPK activity, and MEK1/2 activity. These effects increased in the cells that were exposed to intermittent rather than constant hyperglycemia. These results suggest that fluctuations in glycemic control may be more detrimental to VSMCs than constant high concentrations of glucose.

Research has shown that chronic hyperglycemia enhances
VSMC proliferation and migration and contributes to diabetic atherosclerosis $^{18-21)}$. Studies on animal and human diabetes models have revealed enhanced proliferation of aortic

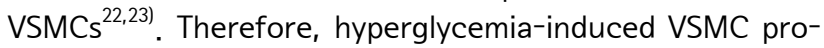
liferation appears to be an important cause of diabetic atherosclerosis. Ceriello et al. ${ }^{24)}$ reported that glycemic variability may directly and significantly participate in the pathogenesis of diabetic vascular complications. Recently, several studies showed that glycemic fluctuation is a major mechanism of the onset of type 2 diabetes and diabetic complications induced by oxidative stress ${ }^{24-29)}$. Other authors mention that glycemic fluctuations affect $\beta$-cell functions and induce cell death ${ }^{26,30)}$.

The MAPK cascade is a highly conserved signaling module that is involved in various cellular activities, including cell proliferation, differentiation, and migration. Extracellular stimuli such as growth factors and environmental stressors induce sequential activation of the MAPK pathway. MAPK modules can be thought of as signaling pathways that collect some kinds of signals from receptors, reactive oxygen species (ROS), and other cellular sensors and then transduce these assorted signals into highly controlled on and off signals, which are passed on to numerous cellular effectors. These downstream effectors mediate critical cellular functions including metabolism, gene transcription in response to stimuli, cell architecture, differentiation, cell survival, proliferation, and apoptosis ${ }^{31)}$. Lo et al. ${ }^{32)}$ demonstrated that a chemoattractant, such as MCP-1, for smooth muscle cells requires both ROS production and ERK1/2 activation in atherosclerosis.

Cultured aortic VSMCs exposed to hyperglycemia show increased proliferation and MAPK activity ${ }^{33)}$. Of note, these effects further increased in our cells that were exposed to 
intermittent rather than constant high glucose concentrations. These findings suggest that glycemic fluctuations could be more deleterious to VSMCs than constant high glucose concentrations. These findings, in combination with other results of this study point to a crucial role of VSMCs exposed to intermittent high glucose concentrations in accelerated VSMC proliferation in diabetes.

On the other hand, the effects of the intermittent high glucose concentration on the proliferation of VSMCs are not fully understood. Hou et al. ${ }^{26)}$ stated that a 72-hour
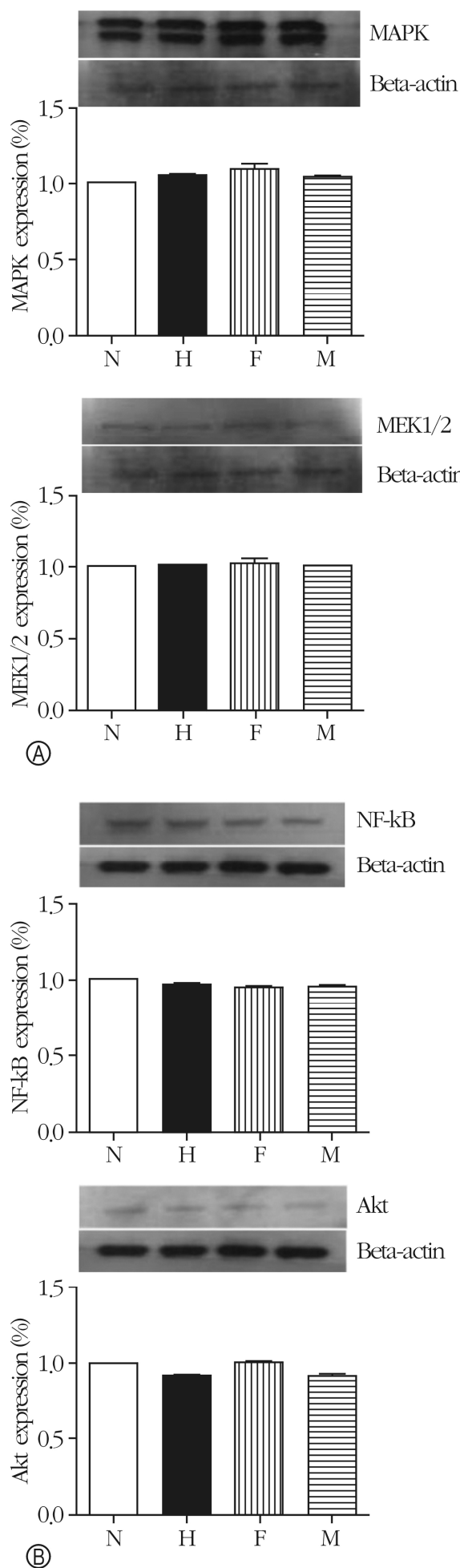
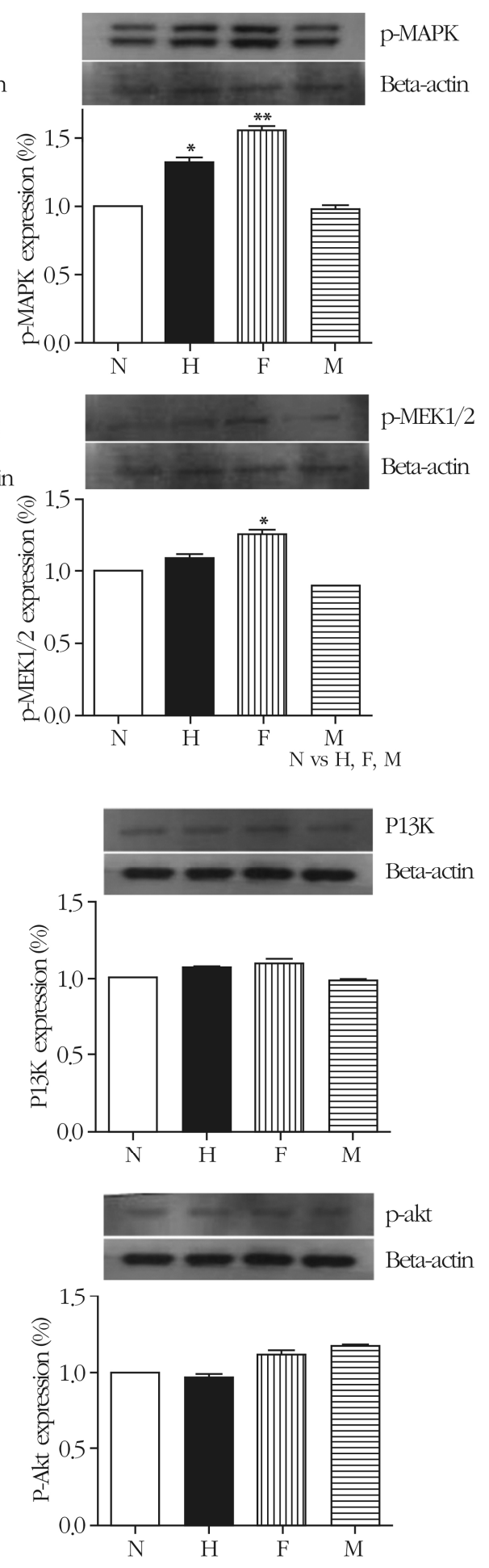

Fig. 3. The effect of glucose fluctuations on the proliferation of vascular smooth muscle cells via the mitogen-activated protein kinase (MAPK) pathway: Western blot analysis. (A) Phosphorylation of MAPK and MEK1/2 were increased in glucose fluctuations compared to high glucose. (B) Phosphorylation of NF-kB, PI3K and akt were not changed. Data are expressed as mean \pm standard deviation from 5 separate experiments. N, normal glucose concentration $(4.8 \mathrm{mM})$; $\mathrm{H}$, high glucose level $(24.5 \mathrm{mM})$; F, fluctuation of glucose between normal $(4.8 \mathrm{mM})$ and high concentrations (24.5 $\mathrm{mM})$; M, mannitol control (11.5 mM); NF-kB, nuclear factor-kappa B; pMEK $1 / 2$, phosphor-mitogen-activated protein kinase kinase 1/2; PI3K, phosphoinositide 3-kinase; akt, Protein Kinase B. ${ }^{*} \mathrm{p}<0.05$ vs. $\mathrm{N},{ }^{* *} \mathrm{p}<0.01$ vs. $\mathrm{N}$. 
exposure to intermittent high glucose induces more serious deterioration of glucose-stimulated insulin secretion than constant high glucose in rat pancreatic islet cells and INS-1 cells. Monnier et al. ${ }^{11)}$ in 2006 reported that the fluctuation of glucose during postprandial periods has a more severe effect on oxidative stress than does constant high glucose concentration. Mesangial cells cultured with a periodic high glucose concentration increase matrix production more than do the cells cultured with stable high glucose concentration $^{10)}$. Similarly, glucose fluctuations have a more adverse effect than does stable high glucose concentration on both tubulointerstitial cells and human renal cortical fibroblasts, in terms of collagen synthesis and cell growth ${ }^{34)}$.

Our study has limitations in terms of complete evaluation of the mechanisms of action of intermittent hyperglycemia on VSMCs. Oxidative stress is known to stimulate atherosclerosis, but we did not test oxidative stress markers. To com- pletely mimic glucose variability in human diabetes, hypoglycemic conditions and a longer incubation with stimulation (hyperglycemia) are needed.

In summary, we found that a constant high glucose concentration increased the proliferation and phosphorylation of MAPK activity in cultured rat aortic VSMCs. The apoptotic signaling did not change during either constant or intermittent hyperglycemia. MAPK activity further increased in cells that were exposed to intermittent rather than constant high glucose concentration, indicating that variability in glycemic control has important pathological effects on the development of diabetic atherosclerosis.

Thus, our results reveal that intermittent hyperglycemia is more deleterious for VSMC proliferation owing to enhanced MAPK activity and points to a potential treatment strategy against diabetic atherosclerosis.
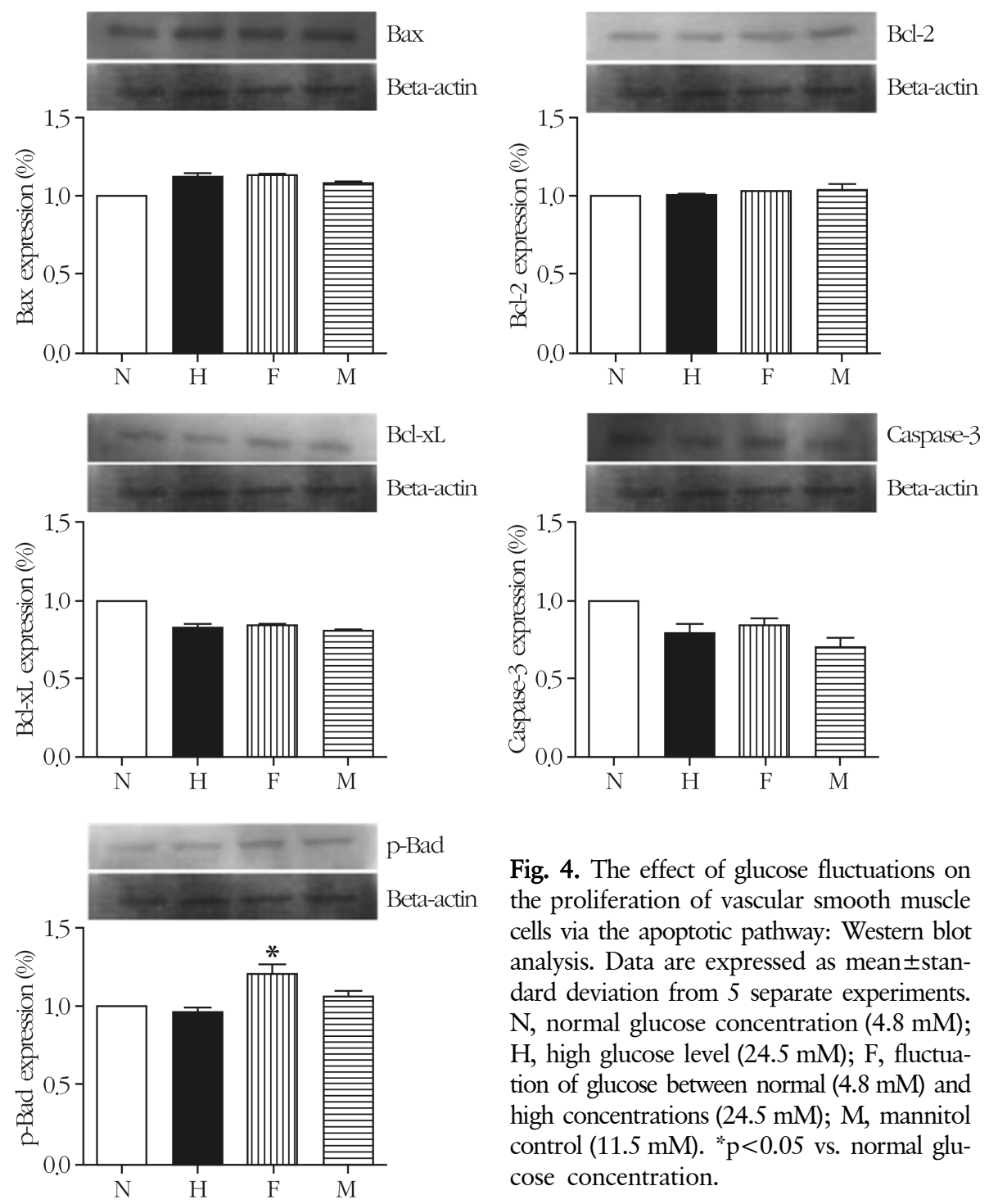

Fig. 4. The effect of glucose fluctuations on the proliferation of vascular smooth muscle cells via the apoptotic pathway: Western blot analysis. Data are expressed as mean \pm standard deviation from 5 separate experiments. $\mathrm{N}$, normal glucose concentration $(4.8 \mathrm{mM})$; $\mathrm{H}$, high glucose level $(24.5 \mathrm{mM})$; F, fluctuation of glucose between normal $(4.8 \mathrm{mM})$ and high concentrations $(24.5 \mathrm{mM}) ; \mathrm{M}$, mannitol control $(11.5 \mathrm{mM})$. ${ }^{*} \mathrm{p}<0.05$ vs. normal glucose concentration. 
Conflicts of Interest Disclosures: The researchers claim no conflicts of interest.

\section{REFERENCES}

1. Beckman JA, Creager MA, Libby P. Diabetes and atherosclerosis: epidemiology, pathophysiology, and management. JAMA 2002; 287:2570-81.

2. Massi-Benedetti M, Federici MO. Cardiovascular risk factors in type 2 diabetes: the role of hyperglycaemia. Exp Clin Endocrinol Diabetes 1999;107 Suppl 4:S120-3.

3. Ruderman NB, Haudenschild C. Diabetes as an atherogenic factor. Prog Cardiovasc Dis 1984;26:373-412.

4. Gaede P, Vedel P, Larsen N, Jensen GV, Parving HH, Pedersen O. Multifactorial intervention and cardiovascular disease in patients with type 2 diabetes. N Engl J Med 2003;348:383-93.

5. Klein R. Hyperglycemia and microvascular and macrovascular disease in diabetes. Diabetes Care 1995;18:258-68.

6. Ceriello A. Postprandial hyperglycemia and diabetes complications: is it time to treat? Diabetes 2005;54:1-7.

7. Ceriello A. Acute hyperglycaemia: a 'new' risk factor during myocardial infarction. Eur Heart J 2005;26:328-31.

8. Ceriello A, Esposito K, Piconi L, Ihnat MA, Thorpe JE, Testa $\mathrm{R}$, et al. Oscillating glucose is more deleterious to endothelial function and oxidative stress than mean glucose in normal and type 2 diabetic patients. Diabetes 2008;57:1349-54.

9. Srivastava AK. High glucose-induced activation of protein kinase signaling pathways in vascular smooth muscle cells: a potential role in the pathogenesis of vascular dysfunction in diabetes (review). Int J Mol Med 2002;9:85-9.

10. Takeuchi A, Throckmorton DC, Brogden AP, Yoshizawa N, Rasmussen H, Kashgarian M. Periodic high extracellular glucose enhances production of collagens III and IV by mesangial cells. Am J Physiol 1995;268(1 Pt 2):F13-9.

11. Monnier L, Mas E, Ginet C, Michel F, Villon L, Cristol JP, et al. Activation of oxidative stress by acute glucose fluctuations compared with sustained chronic hyperglycemia in patients with type 2 diabetes. JAMA 2006;295:1681-7.

12. Sun J, Xu Y, Dai Z, Sun Y. Intermittent high glucose enhances proliferation of vascular smooth muscle cells by upregulating osteopontin. Mol Cell Endocrinol 2009;313:64-9.

13. Liu X, Luo F, Pan K, Wu W, Chen H. High glucose upregulates connective tissue growth factor expression in human vascular smooth muscle cells. BMC Cell Biol 2007;8:1.

14. Folsom AR, Nieto FJ, McGovern PG, Tsai MY, Malinow MR, Eckfeldt JH, et al. Prospective study of coronary heart disease incidence in relation to fasting total homocysteine, related genetic polymorphisms, and B vitamins: the Atherosclerosis Risk in Communities (ARIC) study. Circulation 1998;98:204-10.

15. Yang F, Tan HM, Wang H. Hyperhomocysteinemia and atherosclerosis. Sheng Li Xue Bao 2005;57:103-14.

16. Oltvai $\mathrm{ZN}$, Milliman CL, Korsmeyer SJ. Bcl-2 heterodimerizes in vivo with a conserved homolog, Bax, that accelerates programmed cell death. Cell 1993;74:609-19.

17. Bradford MM. A rapid and sensitive method for the quantitation of microgram quantities of protein utilizing the principle of protein-dye binding. Anal Biochem 1976;72:248-54.

18. Kawamura H, Yokote K, Asaumi S, Kobayashi K, Fujimoto M,
Maezawa Y, et al. High glucose-induced upregulation of osteopontin is mediated via Rho/Rho kinase pathway in cultured rat aortic smooth muscle cells. Arterioscler Thromb Vasc Biol 2004; 24:276-81.

19. Krolewski AS, Warram JH, Valsania P, Martin BC, Laffel LM, Christlieb AR. Evolving natural history of coronary artery disease in diabetes mellitus. Am J Med 1991;90(2A):56S-61S.

20. Sodhi CP, Phadke SA, Batlle D, Sahai A. Hypoxia stimulates osteopontin expression and proliferation of cultured vascular smooth muscle cells: potentiation by high glucose. Diabetes 2001; 50:1482-90.

21. Stamler J, Vaccaro O, Neaton JD, Wentworth D. Diabetes, other risk factors, and 12-yr cardiovascular mortality for men screened in the Multiple Risk Factor Intervention Trial. Diabetes Care 1993;16:434-44.

22. Alipui C, Ramos K, Tenner TE Jr. Alterations of rabbit aortic smooth muscle cell proliferation in diabetes mellitus. Cardiovasc Res 1993;27:1229-32.

23. Oikawa S, Hayasaka K, Hashizume E, Kotake H, Midorikawa $\mathrm{H}$, Sekikawa A, et al. Human arterial smooth muscle cell proliferation in diabetes. Diabetes 1996;45 Suppl 3:S114-6.

24. Ceriello A. The emerging role of post-prandial hyperglycaemic spikes in the pathogenesis of diabetic complications. Diabet Med 1998;15:188-93.

25. Cho JH, Chang SA, Kwon HS, Choi YH, Ko SH, Moon SD, et al. Long-term effect of the Internet-based glucose monitoring system on $\mathrm{HbA1c}$ reduction and glucose stability: a 30-month follow-up study for diabetes management with a ubiquitous medical care system. Diabetes Care 2006;29:2625-31.

26. Hou ZQ, Li HL, Gao L, Pan L, Zhao JJ, Li GW. Involvement of chronic stresses in rat islet and INS-1 cell glucotoxicity induced by intermittent high glucose. Mol Cell Endocrinol 2008;291: 71-8.

27. Olsson MG, Davidsson S, Muhammad ZD, Lahiri N, Tabrizi SJ, Akerstrom B, et al. Increased levels of hemoglobin and alpha1-microglobulin in Huntington's disease. Front Biosci (Elite Ed) 2012;4:950-7.

28. Piconi L, Quagliaro L, Assaloni R, Da Ros R, Maier A, Zuodar $\mathrm{G}$, et al. Constant and intermittent high glucose enhances endothelial cell apoptosis through mitochondrial superoxide overproduction. Diabetes Metab Res Rev 2006;22:198-203.

29. Yu SH, Yu JM, Yoo HJ, Lee SJ, Kang DH, Cho YJ, et al. Antiproliferative effects of rutin on OLETF rat vascular smooth muscle cells stimulated by glucose variability. Yonsei Med J 2016;57:373-81.

30. Kim MK, Jung HS, Yoon CS, Ko JH, Jun HJ, Kim TK, et al. The effect of glucose fluctuation on apoptosis and function of INS-1 pancreatic beta cells. Korean Diabetes J 2010;34:47-54.

31. Hopkins PN. Molecular biology of atherosclerosis. Physiol Rev 2013;93:1317-542.

32. Lo IC, Shih JM, Jiang MJ. Reactive oxygen species and ERK $1 / 2$ mediate monocyte chemotactic protein-1-stimulated smooth muscle cell migration. J Biomed Sci 2005;12:377-88.

33. Natarajan R, Gonzales N, Xu L, Nadler JL. Vascular smooth muscle cells exhibit increased growth in response to elevated glucose. Biochem Biophys Res Commun 1992;187:552-60.

34. Jones SC, Saunders HJ, Qi W, Pollock CA. Intermittent high glucose enhances cell growth and collagen synthesis in cultured human tubulointerstitial cells. Diabetologia 1999;42:1113-9. 